\title{
O DIGITAL NAS HUMANIDADES: UMA ENTREVISTA COM FRANCO MORETTI POR MELISSA DINSMAN ${ }^{\star *}$
}

Melissa Dinsman Tradução: Wander Nunes Frota ${ }^{* * *}$ e Saulo Cunha de Serpa Brandão***

Pelo menos na última década, a expressão "Humanidades Digitais" [doravante, "HD"] tem capturado a imaginação e a ira dos estudiosos em muitas universidades estadunidenses. Os defensores do campo, que funde a Hermenêutica com a Ciência da Computação, o têm como um meio extremamente necessário para agitar e expandir os métodos tradicionais de interpretação literária; para os críticos mais francos, trata-se de uma nova moda que simboliza uma contagem dos feijões neoliberais destruindo o ensino superior estadunidense. Em algum lugar no meio desses dois extremos, há um corpo vasto e variado de trabalho que utiliza e examina criticamente ferramentas digitais na busca pelos estudos humanísticos. Esse campo das HD é imenso e cada vez mais indefinível mesmo por aqueles que o praticam. $\mathrm{Na}$ verdade, a expressão "Humanidades Digitais" parece espantosamente inapropriada para uma área de estudo que inclui, por um lado, a pesquisa computacional, as plataformas de leitura e de escrita digital, a pedagogia digital, as publicações de acesso aberto, os textos aumentados e os bancos de dados literários, e, por outro, a arqueologia da mídia e as teorias das redes, os jogos ["games"] e as plataformas

\footnotetext{
* Nota do editor: Entrevista originalmente publicada na Los Angeles Review of Books. Os direitos de tradução e publicação foram concedidos aos autores e à Texto Digital, respectivamente, pelo editor da $\angle A R B$. Para ler o original em inglês, acessar <https://lareviewofbooks.org/article/the-digital-in-thehumanities-an-interview-with-franco-moretti\#!>.

${ }^{* *}$ Nota dos tradutores: A Profa ${ }^{2}{ }^{a}$ Melissa Dinsman é atualmente Membro Pós-Doutoral do Council on Library and Information Resources (CLIR) em "Curadoria de Dados para Estudos Visuais" na Universidade de Notre Dame (Estados Unidos) e autora de Modernism at the Microphone: Radio, Propaganda, and Literary Aesthetics During World War II (2015) [Modernismo no Microfone: O Rádio, a Propaganda e a Estética Literária Durante a Segunda Guerra Mundial]. A presente entrevista com Franco Moretti foi publicada originalmente na Los Angeles Review of Books (LARB) em 2 mar. 2016.

*** Universidade Federal do Piauí, Brasil. E-mail: wander@ufpi.edu.br

${ }^{* * * *}$ Universidade Federal do Piauí, Brasil. E-mail: brandaosaulo@yahoo.com
}

\section{(c) BY-NC-ND}

Esta obra está licenciada com uma licença Creative Commons.

Texto Digital, Florianópolis, Santa Catarina, Brasil, v. 12, n. 1, p. 119-133, jan./jun. 2016. ISSNe: 1807-9288. 
["wares"], tanto duras ["hard", ou seja, os equipamentos] como moles ["soft", ou seja, os programas]. Como Franco Moretti me disse no início de nossa conversa: "a expressão 'humanidades digitais' nada significa".

Autor de Graphs, Maps, Trees (em português, A Literatura vista de longe) e Distant Reading, ${ }^{1}$ trabalhos devidamente canonizados em termos de HD, se é que tal disciplina exista de fato, é difícil não tomar a afirmação de Moretti pelo seu valor nominal, mas é isso que a série "O digital na área de Ciências Humanas" pretende fazer. Ao longo do presente ano, essa série de entrevistas explorará o papel das HD, bem como o termo "digital" nas Ciências Humanas, ou seja, como ele existe atualmente na academia estadunidense através de conversas tanto com os principais profissionais da área, bem como com os críticos que têm feito colocações contundentes sobre o impacto do [novo] campo na pesquisa humanista. O resultado será algumas linhas surpreendentes de sobreposição, bem como de completa discordância. Mas em seu coração, essa série é um meio para explorar a intersecção entre o digital e as humanidades, e este impacto cruzamentos em pesquisa e ensino, educação superior americana, e a conexão cada vez mais tênue entre a torre de marfim das instituições de elite e o público em geral.

Começo a série de entrevistas com um líder do campo digital, Franco Moretti, professor de Literatura Comparada, atual detentor da cátedra "Danily C. e Laura Louise Bell" e fundador do agora famoso Laboratório de Literatura na Universidade de Stanford, discorre sobre o que ele chama de "erudição dividida", ou seja, sobre tais atribuições que "[não] adicionam [coisa alguma] ao todo". Portanto, seu posto [atual] constitui-se, de fato, em discorrer sobre suas numerosas publicações. Nos últimos 20 anos, ele escreveu, entre outros, os mais "tradicionais" (Modern Epic: The WorldSystem from Goethe to García Márquez [ainda sem tradução para o português]; Atlas do romance europeu 1800-1900, e O burguês), bem como os "computacionalmente inclinados" (A Literatura vista de longe e Distant Reading). Embora Moretti não pareça

\footnotetext{
${ }^{1}$ Nota dos tradutores: O título, Distant Reading, dessa obra de Moretti (ainda não traduzida para o português), é antonímico em relação à expressão "close reading" ("explication des textes", em francês). Nessa obra, Moretti avança e explica muitos pontos de A Literatura vista de longe; a maior parte dos capítulos de Distant Reading foi previamente publicado (entre 1994 e 2011) em importantes revistas como: New Left Review; Modern Language Quaterly; Review; e Critical Inquiry.
}

Texto Digital, Florianópolis, Santa Catarina, Brasil, v. 12, n. 1, p. 119-133, jan./jun. 2016. ISSNe: 1807-9288. 
inteiramente confortável com essa natureza dividida de sua erudição, ele também está firmemente convencido de que isso é uma divisão da qual ele não está disposto a desistir. Essa tensão está presente nos melhores momentos de Moretti nessa entrevista e em seus livros, e é por isso que, apesar de sua estatura muito respeitada tanto no domínio tradicional das Humanidades como no campo das HD, seu trabalho computacional é muitas vezes objeto de muita discussão, até mesmo na Los Angeles Review of Books ( $L A R B)$. Mas essa tensão entre o tradicional e o computacional, entre explicações "próximas" e "distantes" de textos - e Moretti é sempre excelente, tanto na Explicação "próxima" de Textos como [também] na "distante"2 - é [exatamente] o que torna a erudição de Moretti tão impressionante e importante para as Ciências Humanas do século XXI.

\section{Melissa Dinsman: Como eu, você vem de um ambiente estritamente literário, então eu pergunto incialmente como é que você entrou nisso que, por ora, chamaremos de "campo digital"?}

Franco Moretti: Tenho me interessado por uma abordagem científica para a literatura por um longo tempo desde o final da década de 1980, quando escrevi sobre a teoria evolutiva na literatura. A partir daí mudei meu foco para a geografia e escrevi o Atlas do romance europeu 1800-1900. Ao fazer pesquisa geográfica, me dei conta de que os métodos quantitativos ajudaram consideravelmente a confecção de mapas. Então eu me interessei por abordagens quantitativas para a história de todos os tipos. Por volta de 2000, 2001, proferi uma série de palestras na Universidade da Califórnia, em Berkeley, que amarrou todas essas linhas. Isso se tornou o livro A Literatura vista de longe. Mas o momento de sorte foi a fortuita chegada de Matt Jockers ${ }^{3}$ na Universidade de Stanford, como especialista em tecnologia. Nós nos encontramos e começamos a trabalhar juntos. Então, para mim, as HD eram certamente como a quarta ou quinta estação ao longo de uma caminhada, o que também significa que jamais enxerguei as HD como, por assim dizer, uma novidade total, como alguns de seus praticantes costumam fazer. Para mim, as HD são basicamente as formas

\footnotetext{
2 Nota dos tradutores: Jogo de palavras com as expressões "close reading" e "distant reading", reiterando que essa última é o título de um dos últimos livros de Moretti. Ver nota anterior.

${ }^{3}$ Nota dos tradutores: Ver: JOCKERS (2013).
} 
assumidas na era digital pelas abordagens científica, explicativa, empírica, racionalista (chame do que quiser!) da história da literatura e da cultura.

M.D.: É interessante, porque o que você está descrevendo parece uma progressão muito natural, em vez de dizer algo que sempre foi externo ao seu campo de estudo. Nesse ponto de sua carreira, como você descreveria o papel que o digital aponta em seu trabalho? Você usou a frase "humanidades digitais". Você acha que seu trabalho como parte das humanidades digitais ou é algo muito maior?

F.M.: Não. Antes de tudo, a expressão "humanidades digitais" não significa coisa alguma. Crítica Computacional tem mais significado, mas agora todos usamos o termo "humanidades digitais" - eu mesmo inclusive. Eu diria que as HD ocupam cerca de 50 por cento do meu trabalho. Você não pode até não saber, mas quando meus dois últimos livros [à época] estavam para ser publicados - Distant Reading e O Burguês - eu convenci meu editor (e levou algum tempo para convencê-lo) para vê-los sair no mesmo dia, porque para mim eles eram os dois lados da mesma moeda do trabalho que tentei fazer. E o que eu acho potencialmente interessante é que os dois lados não se somam a um todo. Faço as coisas à maneira de Distant Reading que eu jamais poderia fazer à maneira como faço em O Burguês. Mas isso também funciona no sentido inverso. Quando escrevo um livro com conteúdo zero em HD, ou muito pouco, como O Burguês, me vejo fazendo coisas que eu não posso fazer com a outra abordagem. Exatamente quais coisas estão disponíveis em um e no outro e quais coisas são mutuamente exclusivas [de cada uma das abordagens], eu ainda não descobri como pensar sobre isso. Mas, para mim, será esse o problema [grifos no original] para os próximos anos, porque não quero desistir de qualquer uma entre essas duas realidades. Elas são igualmente importantes para mim.

M.D.: Então, não tem havido algo como uma mistura natural em alguma espécie de todo. Ele ainda está muito separado. 
F.M.: É isso. Estou vagamente planejando um livro sobre a forma trágica, que ocasionalmente tento conceber como uma unificação dos dois. Quem sabe? Esses são os planos. É fácil planejar. Fazer é uma coisa diferente.

M.D.: Há alguns subcampos digitais ou da mídia em particular que você acha que produzem maior benefício para as Ciências Humanas e por quê?

F.M.: Não vejo uma área especial. O que eu estaria muito interessado em refletir seria sobre os diferentes destinos, as diferentes fatalidades, até o momento, da abordagem digital na Literatura, na História e na História da Arte, porque as HD têm claramente funcionado de forma muito diferente nos três campos. E por que têm funcionado de forma tão diferente? Muitas das suas perguntas têm a ver com as Ciências Humanas em geral e esta seria uma forma interessante para tentar descobrir por que razão essa abordagem das HD é muito mais produtiva na Literatura do que nos dois outros casos. Não que tenhamos feito a terra tremer, mas é claro que os Departamentos de Inglês [nos Estados Unidos] têm feito mais do que os outros nesse campo. Na verdade, como você sabe, estou atualmente na Suíça, e há várias universidades aqui que estão começando a pensar nesses termos, organizando debates entre historiadores, críticos literários e historiadores da arte. Penso que este tipo de ampliação do panorama é mais frutífero, ao invés de perder-se em minúcias dentro das HD literárias. Nós precisamos disso. É um pouco claustrofóbico em nosso campo.

M.D.: Parte do que você parece estar apontando com a sua discussão sobre a colaboração interdisciplinar se resume ao espaço físico, o que traz à tona um problema interessante e um tanto irônico, relativo à necessidade que têm os projetos digitais de uma quantidade bastante grande de imóveis dentro de uma instituição. Apesar de sua dependência de plataformas on-line, a maior parte da conversa em torno do digital nas humanidades hoje também diz respeito à localização física - i.e., o futuro do trabalho digital está em departamentos individuais ou bibliotecas? Você tem uma opinião sobre o melhor espaço físico para a erudição digital e o que isso diz sobre o futuro papel das HD na universidade? 
F.M.: A resposta empírica é que as bibliotecas estão certamente avançando. Quando você vê as ofertas de emprego [nas universidades], muitas delas estão em bibliotecas ou em ambientes que simulam bibliotecas. Fiz o que eu fiz e me garanto pelo que fiz. Acho que a solução para a pesquisa digital é um laboratório ligado a um departamento. Isso seria tendo o departamento como referência, mas não exatamente como um órgão do departamento. O laboratório teria sua própria autonomia. É claramente uma situação precária e honestamente faria sentido olhar para as Ciências para saber como um Laboratório de Biologia e a função de um Departamento de Biologia funcionam juntos. A forma como vejo esses laboratórios está ligada, mas de maneira co-extensiva ao Departamento - [ou seja,] são como apêndices dos Departamentos.

\section{M.D.: Então, como funcionaria esse espaço separado do Laboratório em termos} de sua ideia de um aumento da visão "panorâmica" das humanidades?

F.M.: No Laboratório Literário de Stanford somos parte de um ambiente de três laboratórios e um dos três é para a pesquisa histórica. Mas de alguma forma [nos Estados Unidos] em Inglês há muitos mais estudantes de pós-graduação do que em História, então não tem havido uma verdadeira sinergia. Na realidade, os laboratórios que funcionam ainda são extremamente raros. Há uma porção de coisas que eles mesmos chamam de laboratórios, mas muitos deles não fazem pesquisa e publicação de laboratório. Portanto, temos de ver como as coisas evoluem.

M.D.: Penso que estamos à beira de falar sobre a relevância das HD para a instituição como um todo e não apenas para departamentos específicos. As pessoas muitas vezes falam de trabalho digital (e mais frequentemente as HD) como um meio de fazer as humanidades relevantes para a universidade do século XXI. Você acha que essa afirmação é uma avaliação justa do trabalho digital e de sua finalidade? Você acha que é justo para as humanidades dizer que as HD virão em um cavalo branco e salvarão as humanidades delas mesmas? 
F.M.: Nem um nem outro. As humanidades terão que salvar-se a si mesmas, e não apenas por causa da razão crassa de que ir para a universidade [nos Estados Unidos] pode custar uma quantidade insana de dinheiro, e assim os estudantes optam por entrar em Administração, Medicina, Economia etc, para refazer o dinheiro [investido] o mais rápido possível. Não é somente isso, apesar de isso não poder ser simplesmente descartado. No século XX, as Ciências Naturais produziram algumas teorias incrivelmente impressionantes e belas em Física, em Genética e em Biologia. As humanidades não produziram nada desse tipo. A Literatura, a Arte, e em um sentido até mesmo a História Política (principalmente de uma maneira acachapante), produziram objetos extremamente interessantes, mas o estudo desses objetos, ou seja, as disciplinas das Ciências Humanas - o estudo da Literatura, o estudo da História - tem ficado para trás. As Humanidades têm ficado para trás na imaginação conceitual e na ousadia. Entendo totalmente por que um jovem de 20 anos iria escolher estudar Astrofísica em vez de estudar Literatura. É muito mais interessante em muitos aspectos, apenas pelo prazer da inteligência. Isso é o que as Humanidades têm que fazer funcionar.

\section{M.D.: Outra solução que é frequentemente apresentada como uma "saída" para as humanidades é um trabalho interdisciplinar, ao qual as HD parecem prestar- se naturalmente.}

F.M.: O trabalho interdisciplinar não resolverá o problema. O trabalho interdisciplinar é ainda mais difícil do que o trabalho disciplinar. É ainda mais incerto, arriscado e aleatório. Você tem que ter muita sorte porque você se move às cegas. Agora, as HD estão seguindo no sentido de se tornar um todo relevante (vamos dizer a Literatura, no meu caso) em termos de belas teorias e conceituação de alta ordem? Não. Ainda não, pelo menos. Isso é o que me interessa. Não me importo se as Humanidades têm gráficos de barras em todos os jornais, como o Financial Times, que eu acho que em um jornal deveria haver, mas não necessariamente em se tratando de Literatura. Não, para fazer as humanidades relevantes que você precisa de algo muito maior do que as HD. O que as Ciências Humanas precisam são grandes teorias e conceitos em negrito. 
M.D.: Outra queixa muitas vezes apresentada contra as HD é que elas são um sinal do crescente neoliberalismo das instituições acadêmicas [no Primeiro Mundo]. Por exemplo, em uma postagem na internet intitulada "The Dark Side of Digital Humanities" ["O lado escuro das HD"], o estudioso dos media Richard Grusin enxerga conexões entre o surgimento das HD e o aumento da "neoliberalização e do corporativismo do ensino superior". Você acha que essa comparação tem algum mérito? Existe algo sobre o desejo das HD de produzir algo que cria um alinhamento com o pensamento neoliberal?

F.M.: As HD não são mais produtivas do que as Ciências Humanas em geral, de modo que, certamente, não é isso. Há definitivamente uma ofensiva neoliberal contra as universidades e um componente importante disso é que, basicamente, mais e mais sectores da pesquisa são convidados a encontrar dinheiro fora da universidade. As HD estão desfrutando de muitas concessões, e por isso as HD podem ser vistas como tendo muita saída nessa nova era. Mas as HD não são parte do ataque. É simplesmente por causa da política de agências de fomento à pesquisa que as HD sofrem menos com o ataque. Não vejo as HD como tendo uma agenda política de qualquer forma alinhada com o crime neoliberal. Pense em uma coisa: As HD estão introduzindo nas Ciências Humanas o trabalho em grupo, de forma sistemática. Podese afirmar que o trabalho em grupo é na verdade o oposto do ethos individualista, [ou seja,] à competição a todo custo, típico das universidades. Isso quer dizer que as HD têm uma inclinação socialista? De jeito algum. É que essa é a maneira que [as HD] têm que funcionar se elas querem realmente funcionar. $\mathrm{O}$ artigo de Grusin tem [nele] uma porção de bom senso. Mas o argumento geral de que as HD estão alinhadas com as grandes empresas de tecnologia simplesmente não é verdade.

M.D.: Isso nos leva à questão do financiamento. Para montar um sólido grupo de pesquisa em HD, é necessária uma quantidade razoável de financiamento. Como é que esse financiamento é tipicamente alcançado? As universidades estão dispostas a pagar por projetos de HD, apesar de cortes maciços em outros 
setores, ou tal financiamento é mais provável de ser encontrado em fontes externas?

F.M.: Honestamente, não sei dizer. Você terá que perguntar aos outros entrevistados. Posso dizer-lhe que, quando lançamos o laboratório recebemos 20 mil dólares da Universidade de Stanford para os dois primeiros anos, com os quais tivemos que comprar tudo: computadores, monitores e para todas as outras despesas. Em seguida, houve mais dinheiro que veio, parte da universidade, parte de alguns subsídios, que são geralmente doações internacionais. Mas você sabe, seis anos depois ainda não temos nem um programador nem um bibliotecário arquivista. Nem sequer temos $10 \%$ de um programador ou de um bibliotecário. Temos um estudante de pós-graduação que é um grande programador e há um professor assistente de Inglês que [também] é um grande programador, mas não temos um programador dedicado. Houve dinheiro que veio, e continuará a vir no futuro, tanto de dentro como de fora da instituição. Desperdicei uma quantidade enorme de tempo juntando o dinheiro para que o laboratório possa apenas sobreviver. Tenho certeza que existam lugares em que seja mais difícil fazer isso e lugares melhores. Mas eu só posso falar do que aconteceu na Universidade de Stanford.

M.D.: Acho que será útil ver como diferentes instituições estão chegando a essa questão do financiamento de forma diferente. Da minha experiência não parece ser consenso sobre a forma de financiar ou de abrigar laboratórios digitais e núcleos de pesquisa. Muitas vezes parece que as pessoas estão fazendo isso de acordo com as circunstâncias, e isso inclui determinar quais fontes estão disponíveis. Vamos mudar de marcha, agora, e falar sobre programação de computadores. ${ }^{4}$ No passado houve uma linha traçada nas HD entre aqueles que são habilitados para programar computadores e aqueles que não o são. Você acha que o engajamento total com as HD requer habilidades de programação e,

\footnotetext{
${ }^{4}$ Nota dos tradutores: Como linguajar técnico específico da área de computação, o substantivo "coding" no texto significa "programação"; por sua vez, o verbo "to code" significa efetivamente "elaborar programas de computador capazes de atuar na resolução de problemas, utilizando linguagem computacional".
}

Texto Digital, Florianópolis, Santa Catarina, Brasil, v. 12, n. 1, p. 119-133, jan./jun. 2016. ISSNe: 1807-9288. 
se assim for, a programação [computacional] deveria tornar-se um requisito para os alunos de Humanidades?

F.M.: Eu não programo computadores e se alguém dissesse que eu realmente não pertenço a essa nova área, gostaria de tentar argumentar que tivessem clemência para com as pessoas que já estavam muito velhas para aprender programação, mas entenderia. E não é apenas uma questão de "vamos lá, deixe-me entrar, porque já fiz muito para dar respeitabilidade ao campo". Não é isso. É que essa programação - e vejo isso em jovens estudantes de pós-graduação ou em colegas mais jovens - lhes permite ter um tipo de inteligência e intuições que eu não tenho e que jamais terei. É uma inteligência que toma a forma de escrever um script, mas na escrita do roteiro há também o início de um conceito, que muitas vezes não se expressa como conceito, mas que você pode ver que ele estava lá a partir dos resultados que a programação produziu. Talvez o melhor exemplo no caso do Laboratório Literário [de Stanford] foi o "Panfleto n. 4", que foi escrito por dois estudantes de pós-graduação que inventaram sua própria forma de script. Tenho inveja dessa forma de inteligência, [mesmo] sabendo que eu nunca a terei. E gosto de ter inveja disso. Penso que, na verdade, muitos dos resultados mais promissores no futuro virão de scripts que são metade scripts, metade cultural, metade literário, ou metade conceito histórico. E então acho que as universidades que têm cursos (de concentração maior ou menor) em HD devem se certificar de que todo mundo tenha chance de ter esse tipo de inteligência.

M.D.: Uma vez que essa entrevista é para o Los Angeles Review of Books, uma publicação que se estende para além de um público estritamente acadêmico, gostaria de saber qual é a sua impressão de como o público em geral entende o termo "humanidades digitais" ou, mais amplamente, como a obra digital que está sendo feita nas ciências humanas (se de fato está)? Se você estiver em um avião e você falar com a pessoa ao seu lado e disser: "trabalho na área das HD em Stanford", você ganha um olhar vazio? O que você acha que é a sua base de conhecimento? E você acha que eles [o público em geral] devem saber que há toda essa tendência ou campo emergindo das Humanidades? 
F.M.: Eles [as pessoas a quem a entrevistadora se refere] devem saber se vale a pena conhecer as HD. Mas essa decisão não pode ser minha. Isso deve ser a sua decisão e você decidiu que eles devem ser informados de uma forma ou de outra. E o que eu estou dizendo se aplica à Literatura e à Arte mais do que à História. Ainda é muito normativa a maneira pela qual, através dos jornais, o público em geral toma conhecimento dos estudos literários ou das abordagens em torno da Literatura. Você lê comentários que informam se um livro ou um filme é bom ou ruim. E o mesmo para as mostras de arte, e assim por diante. No campo da Literatura, as HD são tão nãonormativas como se poderia esperar. É muito mais na direção do explicativo ou do explanatório. Então, para tornar as HD interessantes para o público em geral, seria necessária uma grande revolução na maneira pela qual os media abordam a literatura. Será que essa revolução acontecerá? Não. Deveria essa revolução acontecer? Não tenho lá muita certeza disso. Dediquei minha vida à explicação em vez de ao juízo de valor. Por outro lado, não estou certo de que, para a sociedade em geral, para o mundo em geral, a explicação é mais importante do que o juízo de valor. Penso que é mais importante para as pessoas que dedicam suas vidas tentando entender como as coisas funcionam. Sei que nunca tive tantos mal-entendidos colossais como tive em entrevistas a jornais sobre as HD, ou em artigos de jornal sobre o meu trabalho nessa área.

\section{M.D.: Por que você acha que os jornais não estão entendendo?}

F.M.: Os jornais têm uma abundância de bons escritores que resenham livros, filmes, peças etc, e depois há esses intelectuais nos Departamentos de Inglês [das universidades estadunidenses] fazendo esses cálculos que parecem completamente fora de questão. Penso que isso pode ser o problema. Isso pode ser, sim. Parece uma estranha perda de tempo. Mas não quero me colocar na cabeça dos jornalistas.

\section{M.D.: Assim, talvez as HD sejam muito estranhas para os jornalistas que normalmente escrevem sobre literatura e cinema.}

F.M. Isso é provavelmente uma boa maneira de colocar essa questão. 
M.D.: Assim, estamos agora na minha última pergunta para você, embora ainda tenhamos a questão surpresa que você formulou e que aparecerá no final. Quero continuar esse enfoque sobre a relação do público com a academia através do trabalho digital, mas pensar nisso em termos de "intelectualismo público". Estamos supostamente em uma era que se tem visto um declínio no "intelectual público" (como Nicholas Kristof opinou em The New York Times recentemente, no ano passado). Qual é o papel que tem o trabalho digital, se é que tem algum? Poderiam as HD (ou o digital na área de Ciências Humanas) serem uma ponte muito necessária entre a academia e o público, ou isso é talvez esperar muito de uma disciplina?

F.M.: Troquei a Itália pelos Estados Unidos há 25 anos e, nessa ocasião, já tinha 40 anos de idade, então já havia trabalhado por um tempo. Tinha publicado um par de livros e tinha escrito aqui e ali para jornais. Quando saí, eu talvez me descrevesse como um intelectual. Agora, eu não sou. Sou certamente um professor - alguém muito mais confinado em uma especialidade. $E$ acho que as HD me tornaram mais professor do que era há 15 anos, porque isso [de ser professor] requer muito conhecimento técnico e uma troca entre você e seus pares. Não acho que as HD agora, ou no futuro previsível, são particularmente uma boa aposta para revitalizar o intelectual público. Intelectuais públicos podem ser revitalizados se a política for revitalizada, e honestamente os sinais nesse sentido são escassos, para dizer o mínimo - não só nos Estados Unidos, mas também na Europa.

Agora a minha pergunta para você. Eu estava entretido muitas vezes em suas perguntas, com expressões como "poderia", "deveria", "é provável que", "no futuro", "o propósito" etc, e muito pouco, se alguma coisa, se referia ao passado. Não havia uma única pergunta que perguntasse [algo como]: "Será que as HD não fizeram coisa alguma?" Deixe de lado o que elas podem fazer no futuro; elas fizeram alguma coisa? $E$ eu acho isso fascinante. De alguma forma as HD conseguiram garantir para si mesmas essa infância sem fim, na qual elas são sempre uma promessa de futuro. E, claro, isso se reflete muito na cultura da concessão [de ajuda financeira] que as 
suportam. As concessões [de ajuda financeira] representam tudo que você promete que fará nos próximos três anos, o que é uma forma de pedir para ser enganado ou de incentivar a arte de vender. É uma perversão de juízo intelectual. Tal juízo deve julgar o que foi feito, e não ser apenas uma promessa para o futuro. Deve haver um pouco de espaço para isso, mas só um pouco. A resposta que eu daria a minha própria pergunta, mas que você deve perguntar a outras pessoas, se você achar que é importante (...).

M.D.: Acho que farei isso. Trata-se de um ponto cego no meu próprio pensamento sobre a localização do digital no trabalho realizado pelas Humanidades.

F.M.: (...) É que os resultados até agora têm sido abaixo das expectativas. Agora, é verdade que o campo está no início ainda. É verdade que muito da pesquisa científica é dessa forma chamada de ciência normal, e é certamente verdade que a Crítica Literária tradicional não está enviando faíscas a cada dia. Tudo isso é verdade, mas também é irrelevante, porque as HD estão reivindicando ser a grande novidade e até agora eu acho que produziram pouca evidência sobre isso. Não desejo empurrar isso à exaustão. Não quero dizer que não há provas, porque é complicado. As evidências vêm em muitas formas. Às vezes é refinamento conceitual e às vezes corroboração é uma forma de evidência, e é uma forma importante de evidência. Mas na área de Humanas, muitas vezes, não é considerada importante. Talvez uma das coisas mais importantes que as HD devem incluir na fase seguinte é a natureza de seus próprios resultados - como avaliá-los - e, se necessário, por que é, considerando a quantidade de energia, talento e ferramentas que entram nelas, que temos tanta dificuldade em produzir grandes resultados. Acho, e penso que outros no campo concordariam, que nosso trabalho poderia ter sido melhor.

M.D.: Acho que é uma prova de força pensar perpetuamente "que seria melhor". Acho que é o sinal de um campo em crescimento. $E$ acho que isso é o que nos dá um foco voltado para o futuro. Há uma necessidade perpétua para torná-lo melhor, mais preciso, a fim de construir a disciplina. 
F.M.: Eu concordo. Mas, novamente, pense nisso: para torná-la [a disciplina] melhor - é uma expressão perfeita, porque é uma comparativa, foi bom e agora é melhor não é assim que as Humanidades pensam em geral. É geralmente muito mais do que uma polêmica, é uma questão de tudo ou nada. É um conflito de interpretação, do tipo: "você pensou que Hamlet era o protagonista em Hamlet, quão tolo de você [pensar assim]; o protagonista é Osrico". As HD não funcionam dessa maneira e penso que há algo de muito adulto e muito sóbrio em [elas] não trabalharem dessa forma. Há também alguma coisa, talvez especialmente para as pessoas mais velhas como eu, que é sempre um pouco decepcionante: as HD carecem daquela canção de liberdade - do aborbulhamento do melhor exemplo das antigas Ciências Humanas.

\section{Referências}

DINSMAN, Melissa. Modernism at the Microphone: Radio, Propaganda, and Literary Aesthetics During World War II. Nova York: Bloomsbury Academic, 2015.

JOCKERS, Matthew J. Macroanalysis: Digital Methods and Literary History. Urbana; Chicago; Springfield: University of Illinois Press, 2013.

MORETTI, Franco. A Literatura vista de longe. Tradução: Anselmo Pessoa Neto. Porto Alegre: Arquipélago, 2008.

. Atlas do romance europeu 1800-1900. Tradução: Sandra Guardini Vasconcelos. São Paulo: Boitempo, 2003.

Verso, 2007.

Graphs, Maps, Trees: Abstract Models for a Literary History. Londres:

Modern Epic: The World System from Goethe to García Márquez. Londres; Nova York: Verso, 1996.

. O burguês: entre a História e a Literatura. Tradução: Alexandre Morales.

São Paulo: Três Estrelas, 2014.

. Signs Taken for Wonders: On the Sociology of Literary Forms. Londres; Nova York: Verso, 2005. (Radical Thinkers, 7). 
(Org.). O romance, 1: a cultura do romance. Tradução: Denise Bottmann. São Paulo: Cosac Naify, 2009. 